\title{
DESEJO E PODER NUM CORPO DE MULHER: UMA LEITURA DE OS MEUS SENTIMENTOS, DE Dulce Maria Cardoso
}

\section{Alleid Ribeiro Machado*}

Resumo: Este artigo versa acerca da personagem Violeta, protagonista de Os meus sentimentos, de Dulce Maria Cardoso (2005). Para tal percurso crítico-analítico, o texto busca embasamento em alguns conceitos teóricos relativos aos estudos culturais, de gênero e corporalidade. Este último, principalmente, mas não exclusivamente, tem servido como base analitica da literatura de autoria feminina. Além disso, ao cabo, volta-se para o que mais importa na análise literária: o texto literário, na medida em que propõe a observação da personagem em seu campo de atuação.

Palavras-chave: Empoderamento feminino. Corporalidade. Literatura de autoria feminina.

G alardoado em 2005 com o Prêmio da União Europeia para a Literatura, observamos desenrolar-se em Os meus sentimentos a história de Violeta, uma mulher que, após sofrer um acidente de carro e cuja vida está por um fio, começa a rememorar o que tem sido a sua existência, de qualquer forma, revelando o que ela tem sido: uma mulher completamente "inadequada" quer para os padrões de beleza, quer para os paradigmas de comportamento, considerados e elegidos como mais adequados pela sociedade contemporânea.

Violeta chama-nos a atenção por ser uma personagem excessiva, imprópria; tudo nela sobra, transborda. Fisicamente, ela seria muito bem representada, por exemplo, numa tela de Botero. Violeta não cabe no espaço sociocultural de seu tempo. Aliás, ela não cabe em nenhum padrão. A protagonista do romance também não desempenha de forma satisfatória os papéis sociais que seriam "apropriados" ao seu gênero: o de mãe, o de esposa, o de amante, ou mesmo o 
de filha. Nem ao menos é uma boa vendedora de ceras. Violeta é um incômodo. Um feliz incômodo. Por meio dela o leitor talvez seja levado a pensar: Temos de ser? Temos de agradar, de nos adequar aos padrões?

A questão é que Violeta é uma mulher extremamente lúcida, só que quando todos a têm por morta. E é pela visão alterada, formulada entre a consciência e a inconsciência, de uma mulher que está supostamente fora de si que somos conduzidos à lucidez da realidade humana, desta que nos circunda e que nos coloca à prova todos os dias.

Em Os meus sentimentos, o leitor é levado a partilhar, em meio a um discurso que, do ponto de vista estrutural, se ancora em pensamentos fluidos que insinuam flashes de memória, ou mesmo em vocábulos e estruturas sintáticas altamente polissêmicas, os anseios de uma personagem que, ao longo da narrativa, vai abrindo e revelando as páginas de sua vida. Nesse romance, vamos conhecer os sentimentos de Violeta. Daí uma possivel explicação para um título tão intimista.

No entanto, pensemos mais no título do romance.

Em torno dele, notamos que "os meus sentimentos" nos remete a uma expressão dita em ocasiões fúnebres, para anunciar condolências pela morte de alguém. Assim, uma leitura mais profunda em torno dele levar-nos-ia à possibilidade de interpretá-lo por um viés mais polissêmico, conforme sugerido pela teoria dos atos da fala. Para Searle (1979), todo enunciado contém em si um aspecto imediatamente comunicável, que ele nomeia ato proposicional, e outro, por sua vez, implicitamente colocado, chamado de ilocucional. Ao dizermos "os meus sentimentos" em uma situação fúnebre, estamos convencionalmente repetindo uma expressão exclusivamente utilizada nessas ocasiões, a fim de sermos educados. Além disso, atrelada a essa expressão, está a necessidade de "demonstrarmos" que somos sensiveis, que temos compaixão, que somos capazes de compartilhar a dor do próximo. A narrativa de Dulce Maria Cardoso parece flertar com os conteúdos polissêmicos dos enunciados. Vejamos, como exemplo, a rememoração de Violeta acerca da morte de sua mãe, D. Celeste:

[...] a compaixão é a única coisa que podemos oferecer aos outros; os meus sentimentos; obrigada, muito obrigada, um aperto de mão, um abraço, um beijo rápido na face, depende das pessoas, da intimidade, da circunstância do cumprimento, os gestos ainda reservam algumas surpresas ao contrário das palavras que se repetem numa lengalenga, as minhas condolências, ainda era muito nova, os meus pêsames, vamos sentir a falta dela, não merecia ir tão cedo, coitadinha (CARDOSO, 2005, p. 259).

Permeado por uma fina camada de ironia, principalmente quando expressa a falivel condição humana: "dai-nos o sofrimento alheio e livrai-nos do nosso, amém” (CARDOSO, 2005, p. 259), o discurso de Violeta evidencia um desgosto pertinente às relações humanas que, engendradas por palavras que se tornaram vazias, não passam de maçadoras "lengalengas" (CARDOSO, 2005, p. 47). Em última instância, a expressão que intitula o livro leva-nos ao entendimento de que ela também está implicada a diversas circunstâncias, sugerindo uma amplitude no uso do discurso, que pode expressar desde os sentimentos pessoais da protagonista, um clichê ou mesmo ser a expressão mais exata do próprio desejo de evasão sonhado por Violeta. Ao rememorar uma vida de que, na verdade, deveria sentir "vergonha" - "é sempre de nós que temos vergonha, nunca dos 
outros" (CARDOSO, 2005, p. 296) -, a protagonista sonha com um futuro desligado de uma realidade que lhe é insuportável. Nesse sentido, "os meus sentimentos" é uma evocação subliminar, ao mesmo tempo que também é um anúncio do desejo de morte, ao menos física, da protagonista.

A história inicia-se com um acidente inesperado sofrido por Violeta, numa noite de chuva torrencial, ou, mais especificamente, com a lembrança atordoada da personagem "não devia ter saído de casa, não devia ter saído de casa" (CARDOSO, 2005, p. 9). Violeta decide viajar no mesmo dia em que, enfim, consegue vender a casa dos pais, local a todo tempo lembrado como um fardo ruim. Ela é uma mulher que jamais se sentiu amada por seus progenitores, Celeste e Baltazar. O desejo de vender a todo custo a casa onde precisou viver até a vida adulta - "estou satisfeita, vendi a casa, nunca mais lhe pertenço, finalmente livre" (CARDOSO, 2005, p. 24) - reflete o desgosto que tem por um espaço que, via de regra, concentra a memória de um passado envolto em más recordações, configurado, por exemplo, no desconjuntado relacionamento entre seus pais.

Os saltos finos de minha mãe de um lado para o outro no quarto, a pararem bruscamente na borda da cama, ao lado de meu pai, este país não nos merece o cabelo penteado de minha mãe muito perto do rosto de meu pai, o colar de pérolas quase a tocar no ombro dele, escuta-me Baltazar, mas o meu pai já estava longe, já se tinha exilado no hábito de ficar horas no quintal a olhar para os pássaros, o teu pai não está maluco (CARDOSO, 2005, p. 102).

Tal qual uma forma literária em evolução, como considerou Bakhtin (1988), e na esteira do conceito de contemporaneidade "líquida" e "disforme", conforme nos orienta Bauman (2001, p. 9), ao referir-se a esses dois conceitos como "metáforas adequadas quando queremos captar a natureza da presente fase, nova de muitas maneiras, na história da modernidade", o gênero romanesco em Dulce Maria Cardoso faz-se por meio do inacabamento dos sentidos. Além disso, por baixo do plano mais imediato de interpretação dos discursos que formam o tecido ficcional, há camadas mais profundas de significação, que se abrem, por exemplo, para o âmbito ideológico-político português. Nesse sentido, há na narrativa algumas referências à popularmente conhecida Revolução dos Cravos, ao trazer à tona uma reflexão relacionada ao passado nacional, localizado, mais precisamente, no período ditatorial dos anos 1970.

Não é demais lembrar que a ficção contemporânea portuguesa tem se voltado para esse aspecto importante da vida politica de Portugal. No entanto, no caso específico de Os meus sentimentos, a revolução é rememorada não exatamente como momento glorioso da democracia, mas antes pela violência de seus rastros. Conforme nos lembra Margarida Calafate Ribeiro (2012, p. 90), esse tipo de ficção, na qual se enquadraria também a narrativa de Dulce Maria Cardoso, é formado pelo contradiscurso, de modo que "o império e sua herança" podem ser lembrados "tanto com memórias douradas [...] como com memórias cinzentas da brutalidade do colonialismo e da Guerra Colonial que pôs fim ao império". No romance, as memórias em torno do 25 de abril revelam-se neste segundo aspecto referido por Ribeiro. São memórias cinzentas, principalmente metaforizadas na casa dos pais da protagonista. A casa da infância, que poderia ser lembrada como espaço de afetividade, antes, é rememorada, reversamente, como espaço de más recordações, de desprezo, de violência. Da mesma maneira, o rescaldo revolucionário é lembrado como uma experiência traumática da metamorfose da 
vida nacional portuguesa.

Dessa forma, como o romance aponta para certa abertura à relativização da verdade - "a verdade depende do ponto de vista" (CARDOSO, 2005, p. 104) -, notamos que, no plano ideológico, há no romance uma tênue crítica no que se refere aos efeitos diretos da Revolução dos Cravos na vida cotidiana, pois Violeta, como um sujeito representativo do individualismo da modernidade tardia, alienado de suas potencialidades, também irá relativizar os efeitos posteriores à conflagração. Portanto, a seu ver, para longe de qualquer mudança efetiva política ou social levada a efeito pela ou por qualquer insurreição, está a natureza humana e sua falivel condição, imutável em sua essência.

Quaisquer que sejam os efeitos da resistência armada pela revolução, segundo Paiva (2010, p. 2).

[...] todo o esforço viu-se diluido quando, na contemporaneidade, cada sujeito não pode levar adiante os seus projetos libertadores em meio a um sistema que, sustentado pela aura da redemocratização, por sua onipotência, anulou qualquer força de resistência.

Não é por outra razão que Violeta não crê nos esforços da coletividade, colocando em xeque se tais diligências realmente terão valido a pena. A pergunta que lhe parece perturbar a razão é: o que sobrou desse passado? "Não falo de política, falo de natureza que para o bem e para o mal não há revolução que mude" (CARDOSO, 2005, p. 106).

Todo o contexto que forma o entorno de Violeta, ou seja: a familia, os vizinhos, os colegas de trabalho etc.; ou mesmo sua casa, seu bairro, sua cidade, seu país, ou até mesmo seu entorno político, tem suas bases assentes num profundo mal-estar que, por isso mesmo, pode ser muito bem cooptado sob as lentes de teóricos da cultura como Edward Said. Nas primeiras linhas de Reflexões sobre o exílio, o autor discute a questão do mal-estar (sensação de ocupar um lugar inadequado, fora do lugar) relacionando-a ao exílio. Para Said (2003), eminentemente associada à experiência do degredo está a condição dolorosa e fatídica de se estar e se sentir "fora do lugar", vivenciada pelo sujeito deslocado de sua terra natal - seu berço, sua casa.

Nesse romance de Dulce Maria Cardoso, somos envolvidos numa atmosfera caracterizada pela sensação de desconforto que, de certa forma, atravessará toda a narrativa: "a posição em que me encontro, de cabeça para baixo, suspensa pelo cinto de segurança, não me incomoda, o meu corpo, estranhamente, não me pesa, o embate deve ter sido violento" (CARDOSO, 2005, p. 9). É válido sublinhar que, se de um lado, como observamos, a protagonista é marcada por um processo de descontentamento espacial, gerado sobretudo pela lembrança da casa onde viveu, de outro, ela será marcada pela angústia do não pertencimento, ou, em outras palavras, por um autoexilio identitário.

Deslocada de uma identidade socialmente estabelecida como ideal, a narradora-personagem é o reflexo de um sujeito fora do lugar. Essa sensação, sobretudo existencial, partilhada no seio de uma sociedade, como ressalta Eduardo Lourenço (1999), ambiguamente marcada pela nostalgia saudosa e pela melancolia, é atravessada pelo sentimento de incerteza correlacionado a um tempo líquido, disforme, incerto, muito pertinente à nossa época histórica.

É válido ressaltar que a narrativa evidencia ainda uma fina camada crítica em torno de gênero e corporalidade. Há uma atmosfera de isolamento em torno de Violeta que resulta na visualização da imagem de um sujeito "inadequado", tanto para 
os padrões de beleza socialmente estabelecidos como ideais - "sou tão ridícula com os sapatos de salto alto e a saia justa"; "[...] no meu corpo, se aperto aqui arrepanha dali" (CARDOSO, 2005, p. 39, 198) - quanto no que tange aos modelos de comportamento esperados para o gênero feminino - "uma mulher das mais ordinárias"; “[...] conheço de cor o meu aspecto de puta barata" (CARDOSO, 2005, p. 65, 139).

O sentimento de inadequação em Os meus sentimentos, no que se relaciona à construção da personagem protagonista, que, aliás, está longe de ser um modelo idealizado do feminino, abrange, assim, tanto a esfera corporal quanto a comportamental, e projeta-se na rejeição que sente pela sociedade, que a vê como uma mulher promíscua e esteticamente out: "olha aquela gorda perdida de bêbada" (CARDOSO, 2005, p. 12). O mesmo sentimento pode ser alargado para a sua própria família, ou seja, para os seus pais - "está miúda é impossível"; "está miúda só diz disparates" (CARDOSO, 2005, p. 160, 209) -, assim como para sua filha, Dora - "esta noite no restaurante a minha criança repreendeu-me, tem vergonha de mim" (CARDOSO, 2005, p. 37).

Não é por outra razão que, na fronteira da vida com a morte, Violeta acredita que a libertação das frustrações que marcaram os seus dias deve existir num outro plano, numa outra vida, em que poderá flanar levemente, desligada de todo o peso (inclusive corporal) que fora a sua vida. Esse anseio reflete a inabilidade de lidar com a frustração de "não ter sido o que esperavam dela", e representa a única possibilidade, talvez, de descanso, como também de completude, na busca por um amor possivel:

[...] desde sempre, em todo o lado, a qualquer hora, um entendimento, ele está à minha espera na estalagem sobre o mar, avanço, não tenho medo de nada, nem sequer do amor, os meus olhos rasos de felicidade, na minha pele as cicatrizes de todos os meus sonhos, a partir de hoje nada vai ser diferente, à minha frente um mar de tempo sempre igual, a minha canção a tocar eternamente (CARDOSO, 2005, p. 304-305).

Violeta é uma mulher que tem na bebida e no sexo desenfreado os escapes para as suas frustrações. Ela não acredita nos relacionamentos afetivos: "conheço o amor de ouvir falar" (CARDOSO, 2005, p. 41). A protagonista jamais creu na possibilidade de uma união pautada em sentimentos reciprocos: "ainda não deixei de me espantar com os que não conseguem comer ou dormir sozinhos, com os que se queixam da solidão, talvez sejam felizes os que conseguem suportar os outros" (CARDOSO, 2005, p. 22). Os relacionamentos furtivos de Violeta são uma espécie de dom juanismo apressado, vazio, terminados logo após a conquista.

[...] estacionada no parque para camionistas, com os máximos acesos, aguardando a minha presa desta noite, o camionista mais curioso, mais inquieto, uma vez identificada a presa ajo segundo as regras que a minha experiência neste tipo de caça me permitiu construir, sou sempre cautelosa, e numa noite destas não me convém espantar a presa, os homens são os animais mais medrosos que conheço, a minha primeira regra consiste numa troca de papéis, torno-me a presa perfeita de qualquer caçador, mesmo do mais inexperiente, quando tiver saciado a carne não me incomoda que descubram a verdade, até me divirto quando isso acontece (CARDOSO, 2005, p. 29). 
Em termos de corporalidade, o uso do corpo pela protagonista remete a um ato de violência contra ela mesma. Por isso não parece condizer com uma conquista efetiva da liberdade feminina em torno do prazer. Na verdade, o que se nota é o uso negativo e exacerbado do direito de fazer uso de sua sexualidade, de relacionar-se com o outro, ou mesmo com o próprio corpo. O sexo e o prazer realizam-se como um risco a se correr, ou mais propriamente como um ato de violência contra o desprezo estúpido dos pais, ou dos rapazes com os quais mal se relacionou na juventude: "os rapazes gostavam de mim nas matinês [...] quando as luzes do cinema se apagavam os rapazes vinham ter comigo" (CARDOSO, 2005, p. 41, 43). Esse comportamento, que mais parece um protesto, acompanha Violeta desde a sua adolescência, quando se fazia presa fácil para os garotos.

No fim das contas, a narrativa traz à superficie a imagem de uma mulher talhada pela frustração e pelo desamor, que decidiu viajar, inapropriadamente, numa noite de temporal, a fim de levar as ceras depilatórias que prometera às suas clientes: "viajo na noite do temporal" (CARDOSO, 2005, p. 11). Como consequência, acabou por ser "vítima" de um acidente de automóvel, ficando a dúvida, nas entrelinhas da história, se, de fato, ela fora vítima ou responsável por sua morte.

\section{CONSIDERAÇÕES FINAIS}

A leitura do romance Os meus sentimentos, sob o olhar das questões de gênero e corporalidade e sob aspectos de questões relevantes dos estudos culturais, revelou-nos que as memórias de Violeta são talhadas por angústias diversas ligadas a um amplo espectro que merece ser mencionado. Surpreendentemente, vemos emergir das entrelinhas desse livro de Dulce Maria Cardoso a denúncia dos jogos de aparências que permeiam os relacionamentos humanos, das futilidades cotidianas, da superficialidade dos sentimentos. As memórias de Violeta são voláteis. Inesperadamente, transitam pelo perigoso terreno das incertezas, em que precisão e estabilidade soam como um clichê, discurso vazio ou lengalenga. Vemos, assim, assuntos tão ligados à nossa contemporaneidade perscrutarem as páginas do livro em pauta. Consoante nos lembra Said (2003, p. 46), "o exílio é uma fratura incurável entre um ser humano e um lugar natal, entre o eu e seu verdadeiro lar: sua tristeza essencial jamais pode ser superada". Para Violeta, não houve cura para as tristezas que moveram cada um de seus dias até o momento do acidente. Ao adentrar a autoestrada na noite de chuva, a inadequada protagonista tinha consciência de que empreenderia uma última viagem - "rolo sobre as trevas" (CARDOSO, 2005, p. 11) -, e que tal empresa terminaria com a elucidação da última lembrança "rolo pela luz" (CARDOSO, 2005, p. 303).

[...] nenhuma manhã me vai roubar este sonho tão bonito, nunca mais nenhuma manhã, a minha vida um sobressalto no sono continuado do universo, fecho os olhos por um bocadinho, um sono tranquilo, aqui dentro, aqui onde estou, aconteça o que acontecer nada acontece inesperadamente (CARDOSO, 2005, p. 307).

$\mathrm{Na}$ fronteira entre a vida e a morte, Violeta acreditou que a libertação das frustrações que marcaram a sua trajetória deveria existir num outro plano, numa outra vida, em que poderia flanar levemente, desligada de todo o peso (inclusive 
corporal) que fora a sua vida terrestre. No entanto, há um tom de esperança em Os meus sentimentos. Algo que parece plausivel na escrita da autora portuguesa ${ }^{2}$. Afinal, as lembranças de Violeta iniciam-se em trevas, mas se fecham iluminadas. Podemos considerar, portanto, que a rememoração/viagem de Violeta pode ser entendida em dois contrapontos. Se, por um lado, ela lhe rendeu uma experiência sediciosa, por outro, não seria demais forçoso se tentássemos encontrar em meio à história de Violeta algum subsídio que nos desse alguma sensação de conforto. Assim, em meio à tão traumática experiência de mal-estar em face de uma identidade fora dos padrões, as rememorações de Violeta também lhe trouxeram, ao menos, a possibilidade de enfrentar seus fantasmas e medos, funcionando como um bálsamo acalentador. De qualquer forma, após a leitura do texto, e de conhecermos as cicatrizes de uma mulher frustrada pelo desamor, ficamos com a sensação de que a matéria principal a ser tratada é a vida; e, para além dela, só nos resta o inesperado com que são tecidos os nossos dias: "os meus sentimentos".

\section{Agradecimento}

Agradeço, em especial, à professora Marlise, pelo convite para participar do Congresso Letras em Rede e, principalmente, por todo o apoio dispensado durante a realização da minha pesquisa de pós-doutoramento pela Universidade de São Paulo (USP). Agradeço também à Fapesp pelo apoio financeiro.

\section{Desire AND POWER INSIDE A WOMAN Body: A LECTURE about OS MEUS SENTIMENTOS, by Dulce Maria Cardoso}

Abstract: This paper focuses on the character of a contemporary novel Violet, star of Os meus sentimentos, by Dulce Maria Cardoso (2005). To such critical analytical course, the essay seeks grounding in some theoretical concepts related to cultural studies, gender and corporeality. The last, particularly, but not exclusively, of course, has served as analytical base of women's writing Literature. In addition, at the end, back to what matters in literary analysis: the literary text, in which it proposes the observation of character in their field of expertise.

Keywords: Female empowerment. Corporeality. Women's writing.

\section{REFERÊNCIAS}

BAKHTIN, M. Questões de literatura e de estética: a teoria do romance. Tradução Aurora F. Bernardini et al. São Paulo: Hucitec, 1988.

BAUMAN, Z. Modernidade líquida. São Paulo: Jorge Zahar, 2001.

CARDOSO, D. M. Os meus sentimentos. Alfragide: Asa, 2005.

LOURENÇO, E. Mitologia da saudade: seguido de Portugal como destino. São Paulo: Companhia das Letras, 1999.

2 Acerca do estilo, temas e propostas na escrita dos romances de Dulce Maria Cardoso, sugerimos a leitura de Machado (2014). 
MACHADO, A. R. Dulce Maria Cardoso e Júlia Nery: olhares em torno da diáspora portuguesa em França e África. Revista Desassossego, São Paulo, n. 12, dez. 2014. Disponivel em: <http://www.revistas.usp.br/desassossego/article/ view/76210>. Acesso em: 18 jan. 2017.

PAIVA, J. R. de. Revolução, renovação: caminhos do romance português no século XX. In: MARTINS, E. D.; PONTES, R.; BARROS, P. E. L. (Org.). Falas \& textos: escritos de literatura portuguesa. Fortaleza: Universidade Federal do Ceará, 2010.

RIBEIRO, M. C. O fim da história de regressos e o retorno a África: leituras da literatura contemporânea portuguesa. In: BRUGIONI, E. et al. Itinerâncias: percursos e representações da pós-colonialidade. Braga: Universidade do Minho, 2012. Disponivel em: <http://www.ces.uc.pt/myces/UserFiles/livros/1097_ MCR_fim_hist_reg_Itinerancias.pdf>. Acesso em: 18 jan. 2017.

SAID, E. Reflexões sobre o exílio e outros ensaios. Tradução Pedro Maia Soares. São Paulo: Companhia das Letras, 2003.

SEARLE, J. R. Expression and meaning. Cambridge: Cambridge University Press, 1979. 